\title{
PERKEMBANGAN HUTAN RAKYAT DI PROVINSI KALIMANTAN SELATAN
}

\author{
Development Of Community Forest In South Kalimantan Province
}

\author{
Gusti Syahrany Noor \\ Peneliti Balitbangda Provinsi Kalimantan Selatan \\ Jl. Jend. Sudirman No. 14 Banjarmasin 70114 \\ E-mail:syahrany_noor@yahoo.co.id \\ Dikirim; 9 September 2014, direvisi: 29 Oktober 2014; disetujui:12 Desember 2014
}

\begin{abstract}
Abstrak
Tujuan penelitian ini adalah memberi gambaran tentang perkembangan hutan rakyat di Kalimantan Selatan dan informasi tentang sifat dan manfaat kayu hutan rakyat, dengan harapan kayu dari hutan rakyat ini dapat berkembang menjadi salah satu sumber bahan baku pengganti kayu hutan alam sehingga dapat mendukung perkembangan industri pengolahan kayu di Kalimantan Selatan. Penelitian ini menggunakan metode deskriptif dengan pendekatan kualitatif. Hasil penelitian menunjukan bahwa hutan rakyat terbukti sangat bermanfaat baik bagi pemiliknya, masyarakat dan lingkungannya serta bagi pemerintah daerah khususnya dalam rangka memenuhi pasokan kayu bulat untuk lokal. Sampai tahun 2011 luasan hutan rakyat yang dikembangkan oleh pemerintah di Kalimantan Selatan telah mencapai 2.895 ha, dan yang paling luas berada di kabupaten Tanah Laut yakni seluas 935 ha. Jenis kayu yang dikembangkan adalah kayu sengon, jati, mahoni, karet, petai, akasia, galam, kemiri. Sifat-sifat kayu tersebut perlu dipahami dan diketahui sebelum kayu bersangkutan dimanfaatkan baik sebagai bahan bangunan maupun sebagai bahan baku industri, karena sifat-sifat tersebut pada dasarnya sangat menentukan kualitas produk kayu yang akan dihasilkan. Secara tehnis kayu hutan rakyat dapat dimanfaatkan untuk bahan bangunan, komponen perahu/perkapalan dan bahan baku industri.

Kata kunci: perkembangan, hutan rakyat, Provinsi Kalimanatn Selatan
\end{abstract}

\begin{abstract}
The purpose of this study is to provide an overview of the development of community forests in South Kalimantan and information about the properties and benefits of community forest timber, the hopes community forests timber can be develop into a source of raw materials of natural forest wood substitute that can support the development of the wood processing industry in South Kalimantan. The result showed that Community forest proved to be very useful both for the owner, the community and the environment as well as for the government especially in order to meet the timber supply for local. Until the year 2011 the community forest area that was developed by the government in South Kalimantan has reached 2,895 ha, and the most widely are the Tanah Laut district covering 935 ha.The wood species that developed is sengon, jati, mahoni, karet, petai, akasia, galam, kemiri. The properties of the wood needs to be understood and known before the relevant timber used both as a building material or as raw material for the industry, because these properties are basically determine the quality of wood products that will be produced. Technically private community forest wood can be used for building materials, components boat/ship and industrial raw materials.

Keyword: developments, community forests, South Kalimantan
\end{abstract}

\section{PENDAHULUAN}

Peningkatan jumlah penduduk Indonesia, khususnya Kalimantan Selatan telah menyebabkan keperluan akan kayu semakin hari semakin meningkat sementara hutan alam sebagai pemasok utama kayu bulat cenderung semakin menurun potensinya. Untuk itulah pemerintah telah berupaya untuk mengatasinya yang salah satu programnya adalah mengembangkan hutan rakyat. Hutan Rakyat (HR) adalah hutan yang dimiliki oleh rakyat dengan luas minimal 0,25 ha dan penutupan tajuk tanaman lainnya lebih dari $50 \%$ atau pada tanaman tahun pertama terdapat minimal sebanyak 500 tanaman per hektar (Anonim, 2005 dalam Sukadaryati, 2006).
Di Indonesia hutan rakyat sebenarnya sudah berkembang sejak lama di kalangan masyarakat, dan dilakukan secara tradisional oleh masyarakat di tanah/lahan miliknya. Hal ini dapat dilihat dari adanya hutan rakyat yang diusahakan oleh masyarakat itu sendiri tanpa campur tangan pemerintah, baik berupa tanaman satu jenis, maupun dengan pola tanaman campuran.

Pengembangan hutan rakyat merupakan program nasional yang sangat strategis, baik ditinjau dari kepentingan nasional maupun dari segi pandangan global, meliputi aspek ekonomi, ekologi maupun sosial budaya. Berdasarkan ketentuan formal yang ada, pembangunan hutan rakyat sesungguhnya merupakan semangat desentralisasi melalui 
pelimpahan kewenangan dan administrasi dari pemerintah pusat kepada pemerintahan daerah. Pertimbangannya adalah pemerintah daerah (provinsi dan kabupaten) lebih mengetahui keadaan hutan didaerahnya baik potensi maupun persebarannya. Atas dasar itu maka Pemerintah Daerah berperan sangat penting untuk memfasilitasi, mengkoordinasi, dan meregulasi pengembangan hutan rakyat di daerahnya. Harapan pemerintah dengan adanya hutan rakyat selain untuk mencukupi kebutuhan kayu juga berfungsi untuk menanggulangi lahan kritis, konservasi lahan, perlindungan hutan, serta sebagai upaya pengentasan kemiskinan dengan memberdayakan masyarakat setempat.

Perkembangan hutan rakyat saat ini cukup pesat terutama setelah pasar kayu semakin baik dan didukung oleh minat masyarakat/petani yang cukup tinggi untuk menanam jenis kayu-kayuan di lahan perkarangannya, khususnya di Kalimantan Selatan. Hutan rakyat memiliki potensi cukup besar dalam menyediakan kayu bulat baik untuk kebutuhan industri perkayuan maupun untuk keperluan masyarakat. Jenis-jenis kayu yang berasal dari hutan rakyat bervariasi tergantung permintaan atau kayu yang sudah tumbuh secara alami. Setiap jenis kayu memiliki karakteristik atau sifat-sifat tersendiri dan sifat tersebut perlu dipahami dan diketahui sebelum kayu itu digunakan, karena sifat-sifat tersebut pada dasarnya sangat menentukan kualitas kayu bagi suatu peruntukan tertentu.

Tulisan ini bertujuan memberi gambaran tentang perkembangan hutan rakyat di Kalimantan Selatan dan informasi tentang sifat dan mafaat kayu hutan rakyat, dengan harapan kayu dari hutan rakyat ini dapat berkembang menjadi salah satu sumber bahan baku pengganti kayu hutan alam sehingga dapat mendukung perkembangan industri pengolahan kayu di Kalimantan Selatan.

\section{METODE PENELITIAN}

Daerah penelitian merupakan lingkup Kalimantan Selatan. Pemilihan lokasi/kabupaten tempat pengambilan data ditentukan secara disengaja (purposive sampling), dengan pertimbangan bahwa kabupaten tersebut cukup banyak dijumpai hutan rakyat. Penelitian ini menggunakan metode penelitian deskriptif dengan pendekatan kualitatif. Objek penelitian adalah kegiatan hutan rakyat yang ada di kabupaten terpilih.

Data yang digunakan merupakan data primer dan sekunder yang diperoleh melalui survey lapangan dan wawancara dengan responden. Pengambilan responden dilaksanakan secara purposive sampling terhadap pihak-pihak yang relevan. Wawancara dilakukan terhadap responden yang telah mengetahui pelaksanaan dan perkembangan hutan rakyat serta kegunaan kayu. Pengumpulan data skunder dilakukan dengan melalui studi pustaka kebeberapa lembaga, dinas/instansi terkait, serta publikasi lain yang erat hubungannya dengan topik penelitian.

\section{HASIL DAN PEMBAHASAN}

\section{Gambaran Umum Hutan Kalimantan Selatan}

Kalimantan Selatan memiliki luas wilayah daratan dan perairan darat 37.530,52 $\mathrm{km}^{2}$ dan merupakan wilayah yang tersempit dibandingkan dengan provinsi yang ada di wilayah Kalimantan (6,98 $\%$ ) dari luas pulau Kalimantan, yang terbagi dalam alokasi peruntukan ruang kawasan lindung adalah 20,81\% dan luasan kawasan budidaya $79,19 \%$ dari luas wilayah daratan Propinsi Kalimantan Selatan. Secara administratif, Provinsi Kalimantan Selatan mencakup 11 kabupaten dan 2 kota, 138 kecamatan dan 1958 kelurahan. Kabupaten/kota dimaksud adalah Kabupaten Barito Kuala, Banjar, Tapin, Hulu Sungai Selatan, Hulu Sungai Tengah, Hulu Sungai Utara, Balangan, Tabalong, Tanah Laut, Tanah Bumbu, Kotabaru, Kota Banjarbaru dan Kota Banjarmasin. Kota Banjarmasin sekaligus berfungsi sebagai Ibukota Provinsi Kalimantan Selatan.

Luas kawasan hutan Kalimantan Selatan telah mengalami beberapa kali perubahan. Pada tahun 1984 hutan di Kalimantan Selatan, seluas 2.314.720 Ha dan sampai tahun 2009 kawasan hutan tersebut luasnya 1.779.982 hektar sebagaimana tergambar dalam Tabel 1.

Tabel 1. Perkembangan luas kawasan hutan Kalimantan Selatan tahun 1984-2009

\begin{tabular}{|c|c|c|c|}
\hline Tahun & $\begin{array}{l}\text { Luas } \\
(\mathrm{Ha})\end{array}$ & $\begin{array}{l}\text { Persentase } \\
\quad(\%)\end{array}$ & Keterangan \\
\hline 1984 & 2.314 .720 & 61,68 & TGHK (SK Menhut No 247/Kpts-II/1984, 18/12/84) \\
\hline 1991 & 2.142 .653 & 57,09 & $\begin{array}{l}\text { Telaah Ulang Kawasan Hutan (Surat Dirjen Intag No } \\
\text { 11/Korlak2/PPSDAH/1991) }\end{array}$ \\
\hline 1992 & 1.800 .145 & 47,96 & RUTR \\
\hline 1993 & 1.839 .494 & 49,01 & RTRWP (Perda Kalsel No 3 Tahun 1993) \\
\hline 1996 & 1.839 .494 & 49,01 & $\begin{array}{l}\text { Paduserasi (SK Gub Kalsel No } 011 \\
\text { Tahun 1996, 15/4/96) }\end{array}$ \\
\hline 1998 & 1.839 .494 & 49,01 & $\begin{array}{l}\text { Paduserasi (SK Gub Kalsel No } 217 \\
\text { Tahun 1998, 7/7/98) }\end{array}$ \\
\hline 1999 & 1.839 .494 & 49,01 & $\begin{array}{l}\text { Penunjukkan Kawasan Hutan dan Perairannya (SK } \\
\text { Menhutbun No 453/Kpts-II/1999, 17/6/99) }\end{array}$ \\
\hline 2000 & 1659003 & 44,20 & RTRWP (Perda Kalsel No 9 Tahun 2000) \\
\hline 2009 & 1.779 .982 & 47,43 & $\begin{array}{l}\text { Penunjukkan Kawasan Hutan dan Perairannya (SK } \\
\text { Menhut No. SK 435/MENHUT-II/2009) }\end{array}$ \\
\hline
\end{tabular}


Tabel 2. Luas Kawasan Hutan Provinsi Kalimantan Selatan Tahun 2011

\begin{tabular}{|c|c|c|c|c|c|}
\hline \multirow{2}{*}{$\begin{array}{l}\text { Kabupaten/ } \\
\text { Kota }\end{array}$} & \multicolumn{5}{|c|}{ Fungsi Kawasan Hutan } \\
\hline & HL & KSA -KPA & HP & HPT & HPK \\
\hline Tabalong & $86.201,1$ & - & $94.611,6$ & $53.697,8$ & $13.263,1$ \\
\hline Balangan & $66.330,1$ & - & $24.568,5$ & 23,3 & - \\
\hline H.S. utara & - & - & - & - & $41.928,3$ \\
\hline H.S tengah & $22.974,1$ & - & $8.732,1$ & $13.973,2$ & - \\
\hline H.S selatan & $23.919,6$ & 240,4 & $13.162,8$ & - & $18.730,7$ \\
\hline Tapin & $12.188,1$ & & $12.359,2$ & $1.340,3$ & $6.753,9$ \\
\hline Banjar & $29.719,9$ & $92.537,6$ & $81.763,1$ & $25.568,1$ & $2.395,5$ \\
\hline Batola & - & $3.762,3$ & - & - & $8.005,3$ \\
\hline B. Baru & $2.028,6$ & 42,6 & - & - & - \\
\hline T. Laut & $15.861,2$ & $29.015,5$ & $71.659,5$ & $5.291,1$ & $12.174,9$ \\
\hline T. Bumbu & $95.933,7$ & $6.841,2$ & $164.456,5$ & $25.519,4$ & $25.683,1$ \\
\hline Kotabaru & $171.268,6$ & $80.761,5$ & $290.874,6$ & $1.246,8$ & $22.489,2$ \\
\hline B.Masin & - & 83,9 & - & - & - \\
\hline Total & $526.425,00$ & $213.285,00$ & $762.188,00$ & $126.660,00$ & $151.424,00$ \\
\hline
\end{tabular}

$\overline{\text { Sumber: Balai Pemantapan Kawasan Hutan Wilayah V, Dinas Kehutanan Prov. Kalsel, dalam Anonim, } 2012 .}$

Berdasarkan data dalam Tabel 1 tersebut diketahui bahwa kawasan hutan Kalimantan Selatan sejak tahun 1984 sampai tahun 2009 telah berkurang seluas 534.738 hektar. Tingginya angka kehilangan/penurunan tersebut tidak lepas dari pengaruh perkembangan penduduk. Jumlah penduduk yang semakin banyak mengakibatkan naiknya kebutuhan akan produk yang berbahan dasar kayu, yang berasal dari kayu hutan, sehingga menimbulkan berbagai tekanan terhadap hutan, baik secara legal maupun illegal. Pertambahan penduduk juga mengakibatkan meningkatnya permintaan konversi hutan untuk dijadikan lahan perkebunan, pertanian maupun untuk tempat pemukiman dan pembukaan jalan darat. Selain itu adalah adanya tuntutan daerah untuk meningkatkan pendapatan asli daerah sehingga banyak lahan yang dibuka untuk pertambangan batubara, biji besi dan mineral lainnya. Sementara itu berdasarkan data resmi yang dikeluarkan oleh Direktorat Jenderal Planologi Kehutanan, Departemen Kehutanan (Tahun 2009) bahwa laju deforestasi di Indonesia diperkirakan 1,08 juta ha per tahun (20002005). Laju deforestasi ini dikelompokkan berdasarkan kelompok hutan primer, hutan sekunder dan hutan lainnya (hutan hasil budidaya manusia termasuk hutan tanaman baik hutan tanaman industri maupun reboisasi dan penghijauan). Sedangkan menurut Sumargo dkk (2011), laju deforestasi pada periode tahun 2000-2009 adalah sebesar 1,51 juta ha/tahun, dengan laju deforestasi terbesar terjadi di Kalimantan yaitu sebesar 550.586,39 ha/tahun. Di Kalimantan Selatan sampai tahun 2010, angka deforestasi di dalam dan di luar kawasan hutan (hutan primer, hutan skunder dan hutan lainnya) adalah 8.809,20 ha/tahun.

Luas kawasan hutan di Kalimantan Selatan sesuai dengan fungsinya yang tercantum dalam Keputusan Menteri Kehutanan No SK. 435/MENHUT-II/2009 tercatat sebesar 1.779.982 hektar lebih yang tersebar di masing-masing kabupaten/kota seperti pada Tabel 2.

Berdasarkan data dalam Tabel 2 tersebut, kawasan hutan yang digunakan terbanyak pada Hutan Produksi sebesar 762.188 ha, disusul penggunaan Hutan Lindung sebesar 526.426 ha, KSA-KPA sebesar 213.285 ha, HPK seluas 151.424,000 dan penggunaan luas kawasan yang paling sedikit adalah Hutan Produksi Tetap (HPT) sebesar 126.659 ha. Kabupaten yang memiliki kasawan hutan terbanyak adalah kabupaten Kotabaru yakni seluas 566.640,783 hektar sedangkan terkecil berada di kota Banjarmasin yaitu hanya 83,926 hektar. Peta kawasan hutan Kalimantan Selatan tercantum pada gambar 1. 


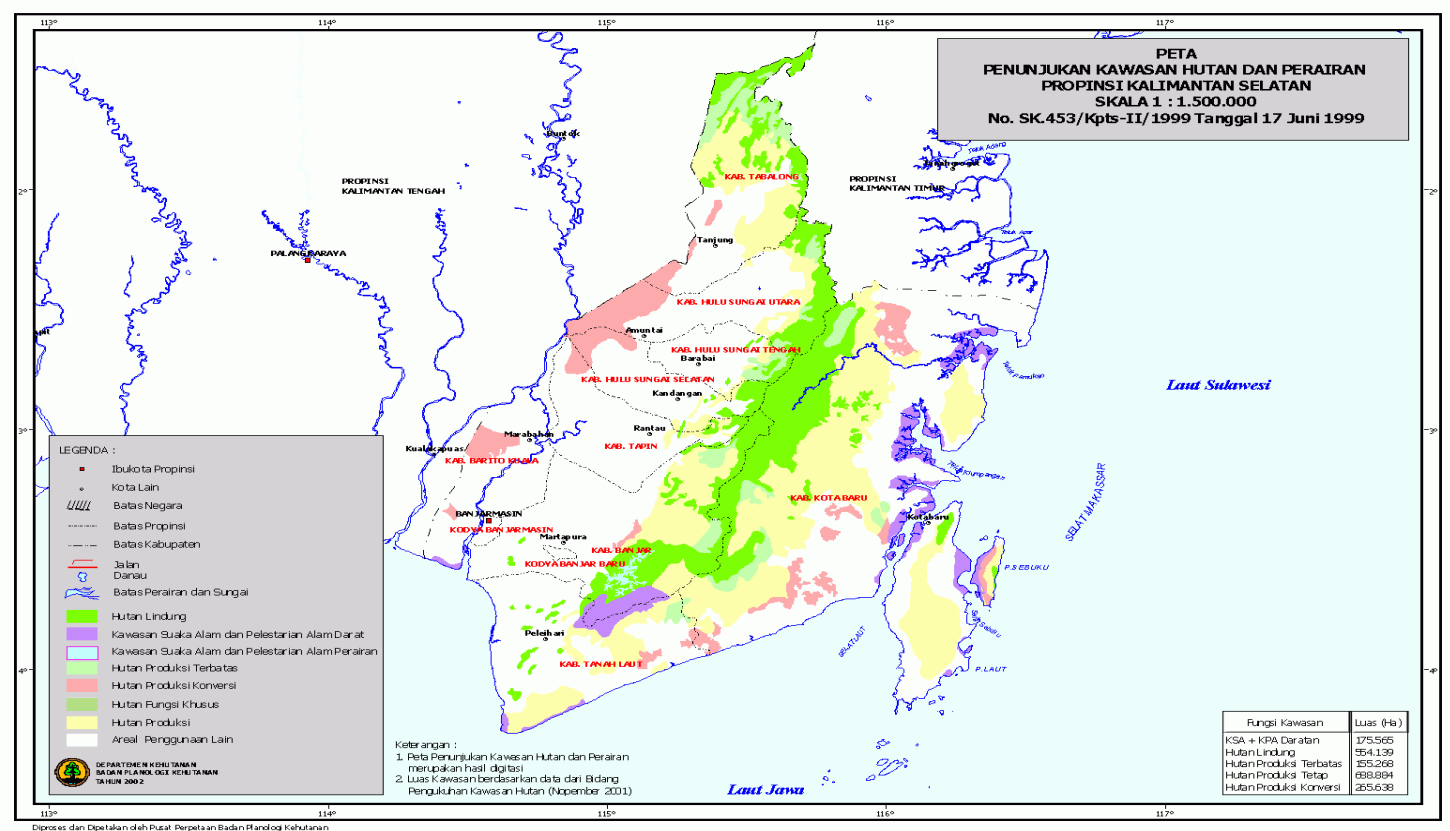

Gambar 1. Peta Penunjukan Kawasan Hutan dan Perairan Kalimantan Selatan

Jenis-jenis kayu yang ada di kawasan hutan Kalimantan Selatan diketahui sangat beragam, dan diperkiraan ada sebanyak 200 jenis kayu dalam satu hektar. Beberapa jenis kayu yang sudah dikenal terutama dalam dunia perdagangan antara lain adalah kelompok kayu meranti merah, meranti putih, meranti kuning, kelompok keruing, ulin, agatis, ramin, sungkai/lurus, medang, mahang, sumpung, alau, pulai, palawan, anglai, durian, laban, balau, dungun, kapur, birik, pantung, pulantan, nyatoh, bangkal, jelutung, damar, perapat, bakau, api-api dan lainnya.

Potensi kayu di Kalimantan Selatan selain berasal dari hutan alam, juga berasal dari hutan tanaman industri ( HTI), hutan tanaman rakyat (HTR), hutan rakyat (HR) dan dari tanaman perkebunan seperti tanaman karet dan kelapa sawit. Hutan tanaman tersebut khususnya penghasil kayu pertukangan diharapkan akan menjadi pemasok utama industri perkayuan di masa mendatang, karena hutan alam sudah tidak mampu lagi memenuhi kebutuhan kayu.

\section{Perkembangan Hutan Rakyat}

Hutan Rakyat (HR) adalah hutan yang dimiliki oleh rakyat dengan luas minimal 0,25 ha dan penutupan tajuk tanaman lainnya lebih dari $50 \%$ atau pada tanaman tahun pertama terdapat minimal sebanyak 500 tanaman per hektar (Anonim, 2005 dalam Sukadaryati, 2006). Hutan rakyat dalam arti yang luas meliputi jaminan atas akses dan kontrol terhadap sumber daya hutan untuk penghidupan masyarakat di dalam dan di sekitar kawasan hutan dimana mereka tergantung terhadapnya secara ekonomi, sosial, kultural dan spiritual.

Pengertian hutan rakyat di luar jawa adalah lahan yang dimiliki rakyat dan di luar konsesi tersebut dan dibebani hak milik dan atau hak lainnya termasuk hutan produksi yang dapat dikonversi dengan dikelola secara intensif dan didominasi oleh tanaman kayukayuan yang dikerjakan secara perorangan, kelompok, atau badan hukum (Dirjen RRL Departemen Kehutanan, 1996).

Menurut Purwanto, dkk. (2004), secara umum ada beberapa karakteristik hutan rakyat antara lain:

1. Luas lahan rata-rata yang dikuasai sempit.

2. Pada umumnya petani berlahan sempit menanam kayu-kayuan dengan tanaman lainnya dengan pola tumpangsari, campuran agroforestri, sedangkan petani berlahan luas yang komersil memungkinkan pengembangan hutan rakyat dengan sistem monokultur.

3. Tenaga kerja yang digunakan berasal dari dalam keluarga.

4. Skala usaha kecil

5. Kontinyuitas dan mutu kayu kurang terjamin.

6. Beragamnya jenis tanaman dengan daur yang tidak menentu atau beragam.

7. Kayu dalam hutan rakyat tidak diposisikan sebagai andalan pendapatan rumah tangga petani tetapi dilihat sebagai "tabungan" yang segera dapat dijual pada saat dibutuhkan.

8. Teknik silvikultur sederhana dan memungkinkan pengembangan dengan biaya rendah, meskipun hasilnya kurang optimal. Namun kontinyuitas hasil dalam horizon waktu dan penyebaran resiko menjadi pilihan petani bagi petani kecil.

9. Keputusan pemanfaatan lahan untuk hutan rakyat seringkali merupakan pilihan terakhir apabila pilihan lainnya tidak memungkinkan.

10. Kayu tidak memberikan hasil cepat, bukan merupakan komoditi konsumsi sehari-hari, membutuhkan waktu lama sehingga pendapatan 
dari kayu rakyat merupakan pendapatan sampingan dalam pendapatan rumah tangga petani.

11. Usaha hutan rakyat merupakan usaha yang tidak pernah besar tetapi tidak pernah mati.

12. Instansi dan organisasi yang terlibat dalam pengelolaan hutan rakyat cukup banyak tetapi tidak ada satupun yang bertanggung jawab penuh atas kelangsungan hutan rakyat.

13. Perundangan, kebijakan, tata nilai, tata prilaku dan sebagainya belum optimal mendukung pengembangan hutan rakyat.

Mengingat pentingnya keberadaan hutan rakyat sebagai sumber daya hutan dan ekonomi maka pengembangan hutan rakyat semakin mendapat perhatian. Departemen kehutanan berdasarkan arah pembangunan jangka panjang kehutanan 2006 - 2025 telah mencantumkan program peningkatan luasan hutan rakyat yang mandiri dan mendukung fungsi hutan sebagai penyangga kehidupan dan kesejahteraan masyarakat.

Pengembangan Hutan Rakyat di Kalimantan Selatan dilaksanakan dengan dana APBD I (Propinsi), DAK-DR/APBD II dan Dana Pemerintah Lainnya. Hasil pelaksanaan pengembangan Hutan Rakyat di Kalimantan Selatan dengan dana APBD Propinsi sejak tahun 2001-2011 tercantum dalam Tabel 3.

Berdasarkan Tabel 3 tersebut jumlah hutan rakyat di kalimantan Selatan dengan menggunakan anggaran APBD provinsi dan DAK-DR/APBD II sejak tahun 2001 sampai dengan tahun 2011 seluas 2.895 ha, dan diketahui yang paling luas berada di kabupaten Tanah Laut yakni seluas 935 ha, kemudian kabupaten Tapin seluas 445 ha, sedangkan yang terendah adalah kabupaten Hulu Sungai Utara yakni 50 ha. Jenis pohon yang ditanam di hutan rakyat tersebut adalah kayu sengon (Paraserianthes falcataria), mahoni (Swietenia macrophylla), jati (Tectona grandis) dan galam (Melaleuca leucadendron), Akasia (Acacia mangium), karet (Hevea brasiliensis), kemiri (Aleurites moluccana), petai (Parkia speciosa), cempedak (Artocarpus integera). Menurut Sendjoto (2008), hutan rakyat di Kabupaten Tanah Laut diusahakan secara monokultur dan multikultur. Hutan rakyat monokultur seperti karet, kelapa, jati dan akasia sementara hutan rakyat multikkultur meliputi beberapa jenis yang diusahakan sesuai dengan kebutuhan pemiliknya.

Menurut Supriadi (2006), luas areal hutan rakyat yang telah ditebang memberikan hasil berupa produksi kayu yang berbeda-beda jumlahnya, tergantung kepada jenis kayu dan luas areal. Sebagai contoh dari 205,22 ha penebangan tanaman sengon menghasilkan $20.551,41 \mathrm{~m}^{3}$, kayu mahoni dari 82,55 ha menghasilkan $8.252,06 \mathrm{~m}^{3}$, kayu jati dari 0,33 ha menghasilkan $32,70 \mathrm{~m}^{3}$. Dengan demikian berarti dalam satu hektar tanaman sengon akan menghasilkan $100,2 \mathrm{~m}^{3}$, satu hektar tanaman mahoni menghasilkan $100,7 \mathrm{~m}^{3}$, dan satu hektar tanaman jati menghasilkan $99,1 \mathrm{~m}^{3}$ kayu bulat. Dengan menggunakan data tersebut maka dapat diassumsikan bahwa potensi kayu bulat dari hutan rakyat dalam satu hektar diperkirakan rata-rata $100 \mathrm{~m}^{3}$. Jika demikian dan berdasarkan data dalam tabel 1 tersebut di atas, berarti di Kalimantan Selatan diperkirakan tersedia potensi kayu bulat dari hutan rakyat sebanyak $289.500 \mathrm{~m}^{3}$. Sementara itu sebagai gambaran bahwa menurut data dari Dinas Kehutanan dalam Anonim (2012), produksi kayu bulat dari hutan rakyat pada tahun 2011 tercatat sebanyak 2 . $889,21 \mathrm{~m}^{3}$

\section{Sifat dan Manfaat Kayu Hutan Rakyat}

Dalam penggunaannya, kayu dipengaruhi oleh sifat-sifatnya, yaitu sifat fisis, mekanis, anatomis, kimia maupun sifat lainnya. Sifat tersebut dipengaruhi oleh jenis kayu, umur pohon, letak kayu dalam pohon, perbedaan tempat tumbuh serta faktor lainnya yang mempengaruhi pertumbuhannya (Brown et al., 1958).

Tabel 3. Rekapitulasi Perkembangan Hutan Rakyat di Kalimantan Selatan tahun 2001-2011 (APBD Provinsi) dan DAK-DR/APBD II

Tahun (Ha)

Kabupaten/Kota

\begin{tabular}{|c|c|c|c|c|c|c|c|c|c|c|c|}
\hline & 2001 & 2002 & 2003 & 2004 & 2005 & 2006 & 2007 & 2008 & 2009 & 2010 & 2011 \\
\hline \multirow[t]{2}{*}{ Kotabaru } & 25 & 25 & 30 & 25 & - & 50 & - & - & - & - & - \\
\hline & & $44^{*}$ & $63^{*}$ & $167 *$ & & & & & & & \\
\hline \multirow[t]{2}{*}{ Tanah laut } & 25 & 25 & - & $75^{*}$ & 50 & 100 & 25 & 25 & 330 & 330 & 25 \\
\hline & & $200 *$ & & & $500 *$ & $75^{*}$ & $150 *$ & & & & \\
\hline Barito kuala & 150 & 25 & 60 & 75 & - & - & - & - & - & - & 25 \\
\hline Banjar & 50 & 25 & 60 & 125 & 50 & 50 & 75 & - & - & - & - \\
\hline Banjarbaru & 25 & 25 & - & 25 & - & - & - & - & - & - & - \\
\hline Tapin & 100 & 25 & 30 & 25 & - & - & - & 50 & 70 & 120 & 25 \\
\hline H.S.S & 50 & 25 & 30 & 50 & - & 50 & - & 25 & - & - & - \\
\hline \multirow[t]{2}{*}{ H.S.T } & 25 & 25 & 30 & $175^{*}$ & $35 *$ & 50 & $75^{*}$ & - & $465^{*}$ & - & - \\
\hline & & & $30 *$ & & & $150 *$ & & & & & \\
\hline H.S.U & 25 & 25 & - & - & - & - & - & - & - & - & - \\
\hline Tabalong & 25 & 25 & 30 & 25 & - & - & - & - & - & - & - \\
\hline \multirow[t]{2}{*}{$\mathrm{J} \mathrm{u} \mathrm{m} \mathrm{la} \mathrm{h}$} & 500 & 250 & 270 & 350 & 100 & 300 & 100 & 100 & 400 & 450 & 75 \\
\hline & & $244^{*}$ & $93 *$ & $417 *$ & $535^{*}$ & $225^{*}$ & $225^{*}$ & & $465^{*}$ & & \\
\hline
\end{tabular}

Sumber; Dinas kehutanan Provinsi Kalsel, 2007 dan 2010 ; Dinas Kehutanan Kab.Kotabaru, 2010; Dinas

Kehutanan, Peternakan dan Perikanan Kab. Hulu Sungai Tengah, 2010 ;Anonim, 2012

$*)=$ DAK-DR/APBD II 
Jenis kayu yang berasal dari hutan rakyat ialah jenis kayu yang diusahakan atau dibudidayakan oleh rakyat dengan lokasi atau tempat tumbuh tidak teratur atau tidak terpola, biasanya ditanam pada areal dekat hutan alam/hutan tanaman atau tanah-tanah negara yang belum dimanfaatkan. Jenis-jenis kayu yang berasal dari tanaman rakyat bervariasi tergantung permintaan pemakai atau tanaman yang sudah tumbuh secara alami. Jenis-jenis kayu yang sering dijumpai di hutan rakyat di Kalimantan Selatan antara lain adalah sengon, karet, jati, galam, mahoni, kayu buah seperti kecapi, cempedak/tiwadak, nangka, kelapa, kemiri, mangga, rambutan dan lain-lain.

Jenis kayu hutan rakyat umumnya merupakan jenis cepat tumbuh dan tidak dirawat serta umur masak tebangnyapun bervariasi bergantung dari kebutuhan pemiliknya. Selain itu batang kayu hutan rakyat umumnya merupakan kayu muda, berdiameter kecil dan banyak cabang. Biasanya kayu yang muda menghasilkan kayu dengan berat jenis rendah, sehingga kayu tersebut kurang kuat dan kurang awet dan mudah diserang oleh organisme perusak kayu. Selain itu diameter kayu hutan rakyat kecil sehingga rendemen penggergajian yang diperoleh relatif sedikit.

Setiap jenis kayu memiliki karakteristik atau sifat-sifat tersendiri baik sifat fisik, mekanik maupun sifat kimia. Secara tehnis sifat-sifat kayu tersebut perlu dipahami dan diketahui sebelum kayu itu digunakan baik sebagai bahan bangunan maupun sebagai bahan baku industri, karena sifat-sifat tersebut pada dasarnya sangat menentukan kualitas kayu bagi suatu peruntukan tertentu.

Sifat-sifat kayu yang perlu diketahui dan dipahami pada beberapa jenis kayu terutama jenis kayu yang ada di hutan rakyat Kalimantan Selatan adalah sebagai berikut:

\section{Kayu Akasia}

Kayu akasia (Acasia mangium) termasuk golongan kayu ringan atau rendah dengan berat jenis antara 0,45-0,75 (Karnasudirdja dan Kadir (1993) dan termasuk kayu kelas kuat III-IV (Anonim, 1994), kelas awet III (Oey Djoen Seng, 1951). Nilai penyusutan kayu aksia dari keadaan basah sampai kering udara pada arah radial 1,65 \% dan arah tangensial 3,87 \% (Nurwati dan Basri, 1990). Akasia mangium pada bagian terasnya lebih gelap dan berwarna agak kecoklatan atau coklat muda hampir menyerupai warna kayu jati, sedangkan bagian gubalnya lebih cerah dan berwarna putih agak kuningan-kuningan, dan berserat lurus.

Menurut Nurwati dan Basri (1990) kayu akasia memiliki keteguhan lentur pada batas patah 728,06 $\mathrm{kg} / \mathrm{cm}^{2}$, modulus elastisitas $104,8 \mathrm{ton} / \mathrm{cm}^{2}$, keteguhan pukul $42 \mathrm{kgm} / \mathrm{dm}^{3}$, keteguhan tekan sejajar serat 338,5 $\mathrm{kg} / \mathrm{dm}^{2}$, keteguhan tekan tegal lurus serat 100,48 $\mathrm{kg} / \mathrm{cm}^{2}$, keteguhan geser arah tangensial $71,8 \mathrm{~kg} / \mathrm{cm}^{2}$, keteguhan belah arah tangensial $115,8 \mathrm{~kg} / \mathrm{cm}^{2}$, keteguhan tarik tegak lurus serat arah tangensial 88,8 $\mathrm{kg} / \mathrm{cm}^{2}$, kekerasan ujung $342,7 \mathrm{~kg} / \mathrm{cm}^{2}$, kekerasan sisi $272,12 \mathrm{~kg} / \mathrm{cm}^{2}$.

Kayu akasia ini tergolong mudah dikerjakan dan mutu pengerjaan halus. Kualitas penyerutan, pembentukan dan pembubutan tergolong sangat baik. Di Kalimantan Selatan kayu ini dijadi bahan bangunan (balok, papan, kaso/reng) dan digunakan sebagai bahan baku industri mebel pengganti kayu jati, karena serat dan kenampakannya hampir menyerupai kayu jati. Kayu ini juga dapat dijadi papan buatan (papan semen, papan partikel,papan/balok lamina).

\section{Kayu Galam}

Kayu galam (Melaleuca leucadendron), termasuk kayu kelas awet III, kelas kuat II, kayunya keras dan berat dengan berat jenis rata-rata 0,85 (OEY JOEN SENG, 1990), kayunya berwarna putih kelabu dengan sedikit merah dan kulit batang yang sudah tua akan tampak seperti terkelupas. Daun galam berbentuk runcing-runcing dengan bunga yang berwarna putih. Kayu galam memiliki kelemahan yakni mudah retak/pecah bila dikeringkan, mudah diserang jasad perusak kayu (bubuk dan rayap).

Kayu galam (Melaleuca leucadendron) dalam keadaan kering udara (Syahrany, 2003) memiliki keteguhan lentur pada batas patah $1014 \mathrm{~kg} / \mathrm{cm}^{2}$, modulus elastisitas 147,9 ton $/ \mathrm{cm}^{2}$, keteguhan tekan sejajar serat $544 \mathrm{~kg} / \mathrm{cm}^{2}$. Kayu galam di Kalimantan Selatan umumnya tumbuh dilahan-lahan rawa dan tanaman ini banyak dijumpai di Kabupaten Barito Kuala. Kayu galam sudah merupakan salah satu bahan baku industri penggergajian di kabupaten tersebut. Kayu ini umumnya dijadikan papan dan balok, arang, kayu bakar dan bahan penopang konstruksi bangunan, bahan untuk siring jalan, komponen perahu.

\section{Kayu Sengon}

Kayu Sengon atau Jeunjing (Paraserianthes falcataria), pada bagian teras berwarna putih atau coklat muda pucat, bagian gubal umumnya tidak berbeda dengan bagian terasnya. Termasuk kayu kurang kuat dan sangat tidak awet dan menurut Martawijaya dan Kartasujana (1977), kayu sengon termasuk kayu kelas kuat IV - V dan dan kelas awet IV/V dengan berat jenis rata-rata 0,33. Nilai penyusutan dalam arah radial dan tangensial berturutturut $2,5 \%$ dan $5,2 \%$.

Kayu sengon dalam kering udara (Martawijaya dan Kartasudjana, 1977) memiliki keteguhan lentur pada batas proporsi $316 \mathrm{~kg} / \mathrm{cm}^{2}$, keteguhan lentur pada batas patah $526 \mathrm{~kg} / \mathrm{cm}^{2}$, modulus elastisitas 44.500 $\mathrm{kg} / \mathrm{cm}^{2}$, keteguhan pukul arah radial $24,1 \mathrm{kgm} / \mathrm{dm}^{3}$, keteguhan pukul arah tangensial 23,6 $\mathrm{kgm} / \mathrm{dm}^{3}$, keteguhan geser arah radial $44,5 \mathrm{~kg} / \mathrm{cm}^{2}$, keteguhan geser arah tangensial $49,5 \mathrm{~kg} / \mathrm{cm}^{2}$, keteguhan belah arah radial $33,6 \mathrm{~kg} / \mathrm{cm} 2$, keteguhan belah arah tangensial $36,4 \mathrm{~kg} / \mathrm{cm} 2$, keteguhan tarik tegak lurus serat arah radial $25,5 \mathrm{~kg} / \mathrm{cm} 2$, keteguhan tarik tegak lurus serat arah tangensial $27,5 \mathrm{~kg} / \mathrm{cm} 2$, kekerasan ujung $222 \mathrm{~kg} / \mathrm{cm}^{2}$, kekerasan sisi $119 \mathrm{~kg} / \mathrm{cm}^{2}$. 
Kayu sengon mudah digergaji, tetapi tidak semudah kayu meranti merah, dapat diserut dan divernis/dipelitur dengan hasil cukup baik. Kayu sengon ini tumbuhnya sangat cepat dan memiliki prospek untuk dikembangkan menjadi salah satu bahan baku mebel di Kalimantan Selatan. Di kabupaten Tanah laut potensi kayu sengon cukup besar dan oleh masyarakat kayunya digunakan sebagai bahan baku mebel seperti lemari dan kursi. Di jawa Barat kayu ini dibuat, balok, papan untuk dijadikan bahan bangunan. Kayu ini juga dapat dijadikan peti kemas, finir kayu lapis, papan buatan dan tangkai korek api.

\section{Kayu Jati}

Kayu jati pada bagian gubalnya berwarna coklat muda, dan warna bagian gubal putih atau kelabu kekuningan. Kayu jati mudah dikerjakan dan divernis dan dipelitur dengan hasil yang baik dan tergolong kayu yang kuat dan lebih awet. Menurut Martawijaya dan Kartasujana (1977) bahwa kayu jati termasuk kayu kelas awet II dan kelas kuat II. Martawijaya dkk, (1981) kayu jati memiliki keteguhan lentur pada batas proporsi $718 \mathrm{~kg} / \mathrm{cm}^{2}$, keteguhan lentur pada batas patah $1.031 \mathrm{~kg} / \mathrm{cm} 2$, modulus elastisitas $127.700 \mathrm{~kg} / \mathrm{cm}^{2}$, keteguhan pukul arah tangensial $21,79 \mathrm{kgm} / \mathrm{dm}^{3}$, keteguhan geser arah radial $80 \mathrm{~kg} / \mathrm{cm}^{2}$, keteguhan geser arah tangensial $89 \mathrm{~kg} / \mathrm{cm}^{2}$, keteguhan belah arah radial $31 \mathrm{~kg} / \mathrm{cm}^{2}$, keteguhan belah arah tangensial $39,8 \mathrm{~kg} / \mathrm{cm}^{2}$, kekerasan ujung $414 \mathrm{~kg} / \mathrm{cm}^{2}$, kekerasan sisi $428 \mathrm{~kg} / \mathrm{cm}^{2}$.

Di Kalimantan Selatan khususnya Kabupaten Tapin, kayu jati ditanam masyarakat dilahan-lahan hak miliki. Kayu jati hasil tanaman masyarakat tersebut sudah ada yang menggunakan sebagai bahan baku mebel ukiran, seperti kursi, meja, toilet, lemari. Tanaman jati yang digunakan untuk mebel tersebut umumnya berumur 20 tahun. Produk mebel yang dihasilkan selain dipasarkan di dalam kabupaten Tapin juga dipasarkan keluar daerah seperti ke Banjarmasin.

\section{Kayu Karet}

Ada beberapa alasan mengapa kayu karet dapat digunakan sebagai substitusi kayu hutan alam dan menjadi andalan dalam memenuhi kebutuhan kayu. Alasan tersebut adalah karena sifat-sifat dasar kayu karet, baik sifat fisik, mekanis maupun kimia relatif sama dengan kayu hutan alam, potensi ketersediaan kayu karet cukup besar sejalan dengan peremajaan perkebunan karet rakyat, dan nilai ekonomis kayu karet cukup baik.

Kayu karet (Hevea brasiliensis) yang baru ditebang berwarna keputih-putihan, kemudian dengan cepat mengalami perubahan warna menjadi berwarna coklat muda agak kepirang-pirangan, sedangkan kayu gubalnya berwarna putih. Kayu ini tidak memiliki batas yang jelas antara kayu gubal dan kayu teras. Kayu karet berserat lurus dengan tekstur beragam dari agak kasar dan rata. Pada bagian yang berdekatan dengan mata kayu, serat kayu sering berpadu sehingga dalam pengolahan diperlukan ketelitian dan peralatan yang sangat tajam agar tidak cacat berupa serat berbulu dan serat patah.

Kayu karet memiliki berat jenis 0,62-0,65 dan kelas kuat II-III. Berarti kayu ini kekuatannya setara dengan kayu ramin, perupuk, akasia, mahoni, pinus, meranti, durian, ketapang, keruing, sungkai, gerunggang, dan nyatoh (Oey Djoen Seng 1990; Budiman 1987; Sutigno dan Mas'ud 1989; Sulastiningsih $d k k$. 1999).

Kayu karet yang berumur 20 tahun, memiliki nilai keteguhan lentur $662,9 \mathrm{~kg} / \mathrm{cm}^{2}$, keteguhan tekan sejajar serat $83,80 \mathrm{~kg} / \mathrm{cm}^{2}$, keteguhan geser 104,87 $\mathrm{kg} / \mathrm{cm}^{2}$ (Sugihartono dan Bangun, 1990). Kayu karet tergolong kayu kelas awet rendah (kelas awet V). Sifat lain yang menarik dari kayu karet adalah mudah digergaji dengan hasil gergajian yang cukup halus, serta mudah dibubut dengan permukaan yang rata dan halus. Kayu karet mudah pecah bila dipaku sehingga perlu hati-hati dalam pengerjaannya. Papan yang tebalnya sampai $2,5 \mathrm{~cm}$ akan menjadi kering udara dalam waktu kira-kira 2 bulan jika dikeringkan dibawah atap. Dalam masa pengeringan kayu karet mudah timbul cacat seperti bengkok, pecah atau menggelinjang. Selain itu, kayu karet mempunyai sifat perekatan yang baik dengan semua jenis perekat industri.

Di Kalimantan Selatan tanaman karet merupakan salah satu komoditi unggulan daerah dan produk utamanya berupa latek. Kayunya sudah dimanfaatkan untuk bahan baku industri mebel dan dijadikan kayu bakar oleh industri kecil seperti pabrik tahu.

\section{Kayu Kemiri}

Kayu Kemiri (Aleurites moluccana), merupakan jenis pohon serbaguna karena hampir seluruh bagiannya dapat dimanfaatkan. Kayunya berwarna kayu putih kekuning-kuningan dan tidak dapat dibedakan antara kayu gubal dan teras. Tekstur kayu agak kasar, arah serat lurus, kesan raba agak kesat, permukaan agak mengkilap. Kayu ini memeiliki berat jenis rata-rata 0,31 dan menurut Martawijaya, et al.(2005), kayu kemiri tergolong kelas kuat IV dan kelas awet IV - V. Kayu ini sangat mudah terserang jamur biru (blue stain) dan organisme perusak kayu lainnya. Meskipun demikian, kayu kemiri termasuk kayu yang mudah dikeringkan, diawetkan, dan mudah dalam pengerjaannya. Kayu ini dapat digunakan sebagai bahan venir inti, tusuk gigi sumpit makan, peti, barang kerajinan (topeng dan wayang golek) dan mainan anak-anak.

Menurut Asdar dan Lempang (2006), pengujian sifat mekanik kayu kemiri yang dilakukan pada kayu dalam kondisi kering udara diperoleh nilai rata-rata keteguhan lentur pada batas proporsi $414,21 \mathrm{~kg} / \mathrm{cm}^{2}$, keteguhan lentur pada batas patah $534,63 \mathrm{~kg} / \mathrm{cm}^{2}$ dan modulus elastisitasnya rata-rata $17.888 \mathrm{~kg} / \mathrm{cm}^{2}$, keteguhan tekan sejajar serat rata-rata $215,66 \mathrm{~kg} / \mathrm{cm}^{2}$, keteguhan tekan tegak lurus serat $48,08 \mathrm{~kg} / \mathrm{cm}^{2}$ dan keteguhan pukul rata-rata $0,47 \mathrm{~kg} / \mathrm{cm}^{2}$. 


\section{SIMPULAN}

Hutan rakyat di kalimantan Selatan merupakan salah satu program pemerintah dalam rangka menanggulangi kekurangan pasokan kayu dari hutan alam, memperbaiki lingkungan dan meningkatkan kesejahteraan masyarakat. Luas hutan rakyat di Kalimantan Selatan yang dikembangkan oleh pemerintah sejak tahun 2001 sampai tahun 2011 seluas 2.895 ha dan yang paling luas berada di kabupaten Tanah Laut yakni seluas 935 ha, sedangkan yang terendah adalah kabupaten Hulu Sungai Utara yakni 50 ha. Jenis kayu yang dikembangkan tersebut adalah kayu sengon, mahoni, jati, galam, akasia, karet, kemiri, petai, cempedak Kayu dari hutan rakyat tersebut telah mampu menjadi alternatif pasokan bahan baku untuk industri pengolahan kayu untuk mencukupi kebutuhan lokal.

Sifat-sifat kayu penting untuk diketahui dan dipahami oleh masyarakat/konsumen agar kegunaan kayu sesuai dengan peruntukannya sekaligus dapat mengurangi ketergantungan konsumen terhadap pemakaian salah jenis kayu tertentu. Kayu yang dikembangkan di hutan rakyat termasuk kelas kuat IIIV, kelas awet II-V dan kayunya dapat dimanfaatkan untuk berbagai keperluan antara lain adalah sebagai bahan bangunan (kusen, papan, jendela, pintu), bahan perahu/kapal, mebel, barang kerajinan/bubutan, papan blok, papan partikel, papan serat, peti, kayu bakar, tangkai korek api, arang kayu, pulp dan kertas.

Perlu ada upaya untuk menambah luasan areal hutan rakyat sehingga potensi kayu untuk mencukupi kebutuhan kayu lokal lebih meningkat dan kesejahteraan masyarakat bertambah. Selain itu, perlu ada kegiatan sosialisasi untuk meningkatkan pengetahuan masyarakat/petani hutan rakyat agar mereka dapat mengetahui tentang sifat dan manfaat kayu yang mereka tanam.

\section{DAFTAR PUSTAKA}

Anonim, 2012. Kalimantan Selatan Dalam Angka. BPS, Kalimantan Selatan, Banjarmasin.

Asdar, M dan Mody,L. 2006. Karakteristik anatomi, fisik mekanik, pengeringan dan Keterawetan kayu kemiri (Aleurites moluccana willd.). journal.unhas.ac.id/index.php/perennial/article/do wnload. Diakses tanggal 25 september 2013

Brown, H.P.,AJ.Panshin and C.C.Forsaith.1958. Texbook of Wood Technology. Mc.Graw-Hill Book Company, New York.

Martawijaya, A., I. Karatsujana, K. Kadir dan S.A.Prawira. 2005. Atlas kayu Indonesia jilid II.Edisi Revisi. Badan Litbang Kehutanan. Dep. Kehutanan. Bogor.

Nurwati dan Sinaga. 1993. Sifat Fisik Beberapa Jenis Kayu HTI. Proceeding Diskusi Sifat dan Kegunaan Jenis Kayu HTI. Badan Litbang Kehutanan, Jakarta.
Oey Djoen Seng. 1990. Berat Jenis dari Jenis-Jenis Kayu Indonesia dan Pengertian Beratnya Untuk Keperluan Praktek (Terjemahan). Puslitbang Hasil Hutan, Bogor.

Martawijaya dan Kartasujana, I. 1977. Ciri Umum, Sifat dan Kegunaan Jensi-Jenis Kayu Indonesia. Lembaga Penelitian Hasil Hutan. Badan Litbang Pertanian, Dep. Pertanian, Bogor.

Purwanto, S. E. Wati dan S. A. Cahyono. 2004. Kelembagaan untuk mendukung pengembangan hutan rakyat produktivitas tinggi. Prosiding Ekspose Terpadu Hasil Penelitian, Puslitbang Bioteknologi dan Pemuliaan Tanaman Hutan,Bogor.

Sendjoto. 2008. Keanekaragaman Tanaman pada Hutan Rakyat di Kabupaten Tanah Laut Kalimantan Selatan.Biodiversitas.mipa.uns.ac.id/D/D0902/D09 0213. Diakses tanggal 8 Juni 2012. 